\title{
LETTERS
}

\section{How well do COPD patients with chronic respiratory failure and their carers adapt to using long-term oxygen at home?}

\author{
${ }^{*}$ Christine Wrench ${ }^{a}$ \\ a COPD Office, Sheffield Teaching Hospitals NHS Foundation Trust, Northern General Hospital, Sheffield
}

\author{
*Correspondence: Mrs Christine Wrench, Specialist Nurse in COPD/ \\ Oxygen Therapy, COPD Office, Sheffield Teaching Hospitals NHS \\ Foundation Trust, 3rd Floor Nurses Home, Northern General Hospital, \\ Herries Road, Sheffield, S5 7AU, UK. \\ Tel: +44 (0)1142 269207 E-mail: christinewrench@blueyonder.co.uk \\ Received 1st September 2011; revised 10th September 2011; \\ accepted 22nd September 2011; online 5th January 2012 \\ (C) 2012 Primary Care Respiratory Society UK. All rights reserved \\ http://dx.doi.org/10.4104/pcrj.2012.00002
}

\section{Dear Sirs,}

A subset of patients with chronic obstructive pulmonary disease (COPD) and significant respiratory failure clearly benefit from longterm oxygen, ${ }^{1,2}$ but little is known about the personal impact of this demanding treatment. We therefore sought to gain insight into the experiences of patients and their carers on commencing long-term oxygen therapy (LTOT).

We adopted a phenomenological approach and the study was ethically approved. Single, semi-structured interviews were carried out by one researcher. COPD patients achieving the criteria for initiation of LTOT who had completed formal oxygen assessment via the nurse-led assessment clinic, plus their carers (defined as having daily contact with the patient), were recruited using purposive sampling. 7 patients ( 6 females and 1 male, mean age 73yrs) and 4 carer participants ( 3 female and 1 male, mean age 53.5yrs) were interviewed.

Interviews were carried out separately and recorded within the participants' own home four weeks following commencement of LTOT using a series of question prompts. Narratives were transcribed and analysed using Colaizzi's seven stage process, ${ }^{3}$ which involved extracting significant statements and identifying common themes to produce an exhaustive description of the phenomenon.

The participants expressed a variety of themes in the narratives of their experiences, and some typical examples are shown in the Table. All described an initial reaction of fear at the recognition of the severity of their chest disease. For some, it served as a reminder of their own mortality. Patients used expressions such as, 'I didn't realise things had got this bad,' with carers talking in terms of 'shock' and 'disbelief'.

One recurring source of negativity towards treatment was prior experience of home oxygen, with two respondents vividly recalling past experiences of terminally ill friends who seemingly had poor quality of life in their final days. This association between their own treatment and past experience served as an additional source of anxiety.

From initial fear, some then talked in terms of disbelief that the treatment was really necessary. Although patient participants had been using their oxygen for four weeks, some remained unconvinced that it was beneficial; this was despite the fact that the clinical reasons for LTOT and the long-term benefits had been discussed at each assessment.

For the carers there was a sense of fear of the unknown in terms of the future. One described her reluctance to take advantage of days when her husband felt well, encouraging him to limit his activity in case he should 'overdo' things.

Feelings of anger and frustration were apparent in both patient and carer accounts. Some expected to adapt immediately, becoming frustrated when their journey of learning took longer than expected. Others held unrealistic views of their physical activity prior to commencing oxygen, describing a perceived loss of independence. Rather than seeing LTOT as something that may increase activity levels, some automatically viewed it as a negative intervention (despite the fact that the positive effects of LTOT had been discussed at previous appointments).

The patient participants related feelings of anxiety about the personal impact of home oxygen but also struggled with feelings of guilt at the impact of their chronic illness on their carers. For the carer participants, this stage was particularly difficult; their role involved providing support for their loved one whilst trying to adapt emotionally to changes in their own lifestyle.

Although new to LTOT, some described coping mechanisms which they had begun to develop, such as breathing exercises and relaxation. Patients and carers also described simple adaptations to daily activities, such as planning use of portable oxygen cylinders, pacing activity and employing breathing control techniques.

The final stage of acceptance involved both patients and carers finding ways of adapting to their treatment. The interviews closed with respondents being asked what advice they might give from their own experience to someone who was about to start home oxygen. Despite initial anxieties, all participants responded positively.

The participants outlined a complex personal journey. Emergent themes included fear, anger, frustration, and finally acceptance through personal adaptation. The narratives described a range of 
Table 1. Examples of participant responses

\begin{tabular}{l|l|l} 
& Patient Participant & Carer Participant \\
\hline Initial Fear & $\begin{array}{l}\text { 'I didn't realise things had got this bad, with my } \\
\text { chest I mean.'( PP3) } \\
\text { II thought I was on the way out. (PP1) }\end{array}$ & $\begin{array}{l}\text { 'It was a shock. I knew it wasn't good if she had to be on it } \\
\text { for 15hrs a day.' (CP2) }\end{array}$ \\
\hline Denial/Frustration & $\begin{array}{l}\text { 'The oxygen doesn't feel part of me yet. I could just } \\
\text { give it up and not have it any more.' (PP1) }\end{array}$ & $\begin{array}{l}\text { 'You feel alright today but what about tomorrow?' } \\
\text { I'll be alright tomorrow.' 'No you won't!' (CP1) }\end{array}$ \\
\hline Perceived loss of independence & $\begin{array}{l}\text { 'I'm just losing it. I'm not able to do things. } \\
\text { My life is this chair.' (PP1) }\end{array}$ & $\begin{array}{l}\text { 'I didn't want her to become dependent on it (oxygen). She used to be } \\
\text { able to get out and about on her own. Now she panics - even if we } \\
\text { are with her.' (CP3) }\end{array}$ \\
\hline Acceptance & $\begin{array}{l}\text { 'Initially you will be scared, like I was, but take it from } \\
\text { me you'll only feel a benefit from using it. It will open your } \\
\text { life completely.' (PP4) }\end{array}$ & $\begin{array}{l}\text { 'I'm never sure whether this will be the last one (exacerbation), you } \\
\text { know, whether he'll get better. But we cope' (CP2) }\end{array}$
\end{tabular}

emotions which echoed the grief process, ${ }^{4}$ with striking similarities between the narratives of patients and carers.

Although we were not able to provide long-term follow-up, none of the patient participants was highlighted on the oxygen providers' concordance reports as being either under- or over-users of their prescribed oxygen at 12 months, suggesting that specialist nurse intervention resulted in appropriate oxygen usage.

As oxygen services continue to develop, specialist input is required to ensure that the rationale for treatment is fully understood. The psychological effects of starting LTOT are significant, with patients and carers expressing a clear sense of loss. Future care planning for patients new to oxygen therapy must acknowledge this. Further studies looking at the experiences of patients and carers over a longer time frame would further enrich our understanding of this phenomenon.
Acknowledgements Dr Rod Lawson, Respiratory Consultant, Sheffield Teaching Hospitals, for his encouragement and help in editing the manuscript. Ruth Darwin, Oxygen Specialist Nurse, Sheffield Teaching Hospitals, for support during data collection phase

Conflicts of interest The author declares that there are no conflicts of interest in relation to this article.

\section{Funding None.}

\section{References}

1. Nocturnal Oxygen Therapy Trial Group. Continuous or nocturnal therapy in chronic obstructive lung disease. Ann Intern Med 1980;93:391-98.

2. Medical Research Council Working Party. Long-term domiciliary oxygen therapy in chronic hypoxic cor pulmonale, chronic bronchitis and emphysema. Lancet 1981;28:681-86.

3. Colaizzi, P. Psychological research as a phenomenologist views it. In R. Valle and S. Keys (Eds) Existential Phenomenological Alternatives for Psychology, 1978, pp48-71. New York: Oxford University Press.

4. Kubler-Ross E. On death and dying. Macmillan, 1969; ISBN 0415040159

\section{Available online at http://www.thepcrj.org}

